\title{
Rheumatoid Arthritis in a North American Native Population: Longitudinal Followup and Comparison with a White Population
}

\author{
CHRISTINE A. PESCHKEN, CAROL A. HITCHON, DAVID B. ROBINSON, IRENE SMOLIK, CHERYL R. BARNABE, \\ SURAJ PREMATILAKE, and HANI S. EL-GABALAWY
}

\begin{abstract}
Objective. To describe differences in phenotype and outcomes in North American Native (NAN) patients with rheumatoid arthritis (RA) followed prospectively and compared to white patients with RA.

Methods. Patients from a single academic center were followed over 20 years using a custom database. Data included diagnoses, year of disease onset, ethnicity, modified Health Assessment Questionnaire (mHAQ) score, patient and physician global scores, tender and swollen joint counts, treatment, serology, and erythrocyte sedimentation rate $(E S R)$. Records of all white $(n=1315)$ and NAN $(n=481)$ patients with RA were abstracted. Cumulative treatment data and clinical measures were compared.

Results. Disease duration was longer in white patients compared to NAN patients (16 \pm 11 vs $14 \pm$ 10 years, respectively; $\mathrm{p}=0.03$ ). Onset age was 34 years for NAN patients and 43 years for white patients $(\mathrm{p}<0.001)$. NAN patients were more frequently positive for rheumatoid factor $(89 \% \mathrm{vs}$ $74 \% ; \mathrm{p}<0.001)$ and antinuclear antibody $(57 \%$ vs $21 \% ; \mathrm{p}<0.001)$. Although mean tender joint counts and swollen joint counts were similar, NAN patients had higher Lansbury scores (weighted joint count; 66.5 vs 49.7; p < 0.001), mHAQ scores (1.1 vs $0.9 ; \mathrm{p}=0.001)$, and ESR (31 vs 25 $\mathrm{mm} / \mathrm{h} ; \mathrm{p}<0.012)$. NAN patients had more frequent knee (53\% vs $34 \% ; \mathrm{p}<0.001)$ and elbow $(62 \%$ vs $48 \%$; $=0.007)$ involvement. Compared to white patients, NAN patients took a higher lifetime number of disease-modifying antirheumatic drugs $(3.2 \pm 1.9$ vs $2.2 \pm 1.7$; p < 0.001$)$, had more combination therapy $(38 \%$ vs $29 \%$; $=0.002)$, and had more frequent prednisone use $(55 \%$ vs $39 \% ; \mathrm{p}<0.001)$.

Conclusion. Compared to white patients, NAN patients with RA develop disease earlier, are more frequently seropositive, have greater large joint involvement, and greater disease burden, although treatment is more aggressive. These differences are present early and persist throughout the disease course. (First Release June 15 2010; J Rheumatol 2010;37:1589-95; doi:10.3899/jrheum.091452)
\end{abstract}

Key Indexing Terms:
RHEUMATOID ARTHRITIS
NORTH AMERICAN NATIVES
ETHNIC GROUPS ETHNIC DISPARITY
North American Natives (NAN) have some of the highest documented prevalence rates of rheumatoid arthritis (RA) in the world, ranging from $2 \%$ to $5 \%$, in diverse populations scattered across the continent $1,2,3,4,5,6,7,8$. A higher frequen-

From the Departments of Medicine, Community Health Sciences, and Immunology, and the Section of Rheumatology, University of Manitoba, Winnipeg, Manitoba; and the Department of Medicine, University of Calgary, Calgary, Alberta, Canada.

C.A. Peschken, MD, MSc, Assistant Professor, Departments of Medicine and Community Health Sciences, University of Manitoba; C.A. Hitchon, MD, MSc, Associate Professor; D.B. Robinson, MD, MSc, Associate Professor, Department of Medicine, University of Manitoba; I. Smolik, PhD, Research Associate; S. Prematilake, MD, Research Assistant, Section of Rheumatology, Department of Medicine, University of Manitoba; H.S. El-Gabalawy, MD, Professor, Departments of Medicine and Immunology, University of Manitoba; C.R. Barnabe, MD, Research Fellow, Department of Medicine, University of Calgary.

Address correspondence to Dr. C.A. Peschken, University of Manitoba Arthritis Center, RR149 - 800 Sherbrook Street, Winnipeg, Manitoba R3A 1M4, Canada.E-mail: cpeschken@hsc.mb.ca

Accepted for publication March 2, 2010. cy of juvenile onset arthritis in NAN is also reported ${ }^{9,10,11}$. There are also reports of higher than expected frequency of rheumatoid factor (RF) and antinuclear antibodies (ANA) in NAN populations; both RF and ANA are known to be markers of severe, chronic disease ${ }^{12,13}$.

Despite these documented differences, information on phenotype, clinical course, and outcomes in NAN patients with RA is lacking. Several studies suggest severe disease, with a high frequency of erosions ${ }^{14,15}$, deformity ${ }^{8}$, and disability $3,16,17$. There are few detailed reports, little information on treatment, and no studies including a control population.

We report the first description of clinical course and outcomes in a large cohort of NAN patients with RA followed prospectively over several years compared to a large cohort of white patients with RA followed at the same center. Manitoba NAN peoples are primarily Cree, Ojibway, and Metis, with smaller populations of Dakota, Dene, Sioux, and

Personal non-commercial use only. The Journal of Rheumatology Copyright (C) 2010. All rights reserved. 
Chipewyan people. Approximately $14 \%$ of the Manitoba population self-identifies as $\mathrm{NAN}^{18}$.

\section{MATERIALS AND METHODS}

The University of Manitoba Arthritis Centre (UMAC) has been maintaining a prospective, longitudinal database for clinical and research purposes on all patients seen at the center since 1990. Patients were cared for by a small group of 3-6 rheumatologists over the years of data collection. The UMAC database includes the patients' diagnoses, year of disease onset, and date of first and each subsequent visit to the Arthritis Center. All diagnostic labels are assigned according to whether patients meet current clinical criteria, and are overwritten if the diagnosis changes. Patients are assigned a diagnosis of RA only if they have met the American College of Rheumatology 1987 revised criteria ${ }^{19}$. The database also includes self-reported data on ethnicity, education, and occupation. At each visit, patients complete a modified Health Assessment Questionnaire (mHAQ) and visual analog scales (VAS) for pain, fatigue, and global disease activity (GDA). Physicians complete tender and swollen joint counts, physician global VAS, and current treatment information, and update serology and acute-phase reactants, if performed. The computerized database program calculates a Lansbury Index, a weighted joint count that takes into account the size of the affected joint ${ }^{20,21}$, for each clinic visit. RF and ANA are generally obtained at the baseline visit, and subsequently repeated if clinically warranted. RF is performed by nephelometry. ANA is measured using immunofluorescence and ELISA. Anticyclic citrullinated antibody (anti$\mathrm{CCP}$ ) was not clinically available at the start of data collection, and is therefore not included in this dataset. The database contains records of 8003 patients with rheumatic diseases as of February 28, 2008.

Records of all patients with a diagnosis of RA or juvenile RA who had self-identified as being of either white or NAN background were abstracted. The 2 cohorts were further divided into those with disease duration of 5 years or less (Cohort 1), between 5 and 15 years (Cohort 2), and greater than 15 years (Cohort 3). For each cohort, age of onset, serology, cumulative treatment data, acute-phase reactants, mHAQ scores, VAS scores, and tender and swollen joint counts and Lansbury scores were compared. Since this is a clinical database, the number of and intervals between clinic visits varied between patients; therefore we have chosen to present mean values and values at the last clinical assessment for these measurements.

Statistical analyses. Analyses were performed using SPSS version 16.0 (SPSS Inc., Chicago, IL, USA). Descriptive analyses of the differences between the 2 ethnic groups were performed with the chi-squared distribution for categorical variables and with t-test for comparison of means for continuous variables.

\section{RESULTS}

Records of 481 NAN and 1315 white patients with RA were abstracted. Of these, 348 were in Cohort 1, 627 in Cohort 2, and 801 in Cohort 3. Gender distribution was not different; close to $80 \%$ of both groups in all cohorts were women. General and individual cohort characteristics are found in Table 1. The mean age at disease onset was 34 years in NAN patients $(\mathrm{SD} \pm 14)$ compared to 43 years $(\mathrm{SD} \pm 17)$ in white patients $(\mathrm{p}<0.001)$. NAN patients were more frequently positive for RF and ANA (89\% vs 74\%, respectively, p < 0.001 ; and $57 \%$ vs $21 \%, \mathrm{p}<0.001$ ). Mean RF titers were also more than twice as high in NAN patients compared to whites $(775 \mathrm{IU} / \mathrm{ml} \mathrm{SD} \pm 1859$ in NAN patients compared to $361 \mathrm{IU} / \mathrm{ml} \mathrm{SD} \pm 558$ in white patients; $\mathrm{p}<0.001$; normal values in our laboratory are $<20 \mathrm{IU} / \mathrm{ml}$ ). The proportion of patients positive for RF rose slightly with increasing disease
Table 1. Selected demographics of North American Native (NAN) and white cohorts. Total $\mathrm{n}=1796$.

\begin{tabular}{|c|c|c|c|}
\hline Characteristics & $\begin{array}{c}\text { NAN, } \\
\mathrm{n}=481\end{array}$ & $\begin{array}{c}\text { White, } \\
\mathrm{n}=1315\end{array}$ & $\mathrm{p}$ \\
\hline \multicolumn{4}{|l|}{ Entire cohort } \\
\hline Onset age, yrs $\pm \mathrm{SD}$ & $34 \pm 14$ & $43 \pm 17$ & $<0.001$ \\
\hline Disease duration, yrs $\pm \mathrm{SD}$ & $14 \pm 10$ & $16 \pm 11$ & 0.03 \\
\hline Female, $\%(\mathrm{n})$ & $79(380)$ & $78(1026)$ & NS \\
\hline RF positive, \% (n) & $89(428)$ & $74(973)$ & $<0.001$ \\
\hline $\mathrm{RF}$ titer, mean $\mathrm{IU} / \mathrm{ml} \pm \mathrm{SD}$ & $775 \pm 1859$ & $361 \pm 558$ & $<0.001$ \\
\hline ANA positive, $\%(\mathrm{n})$ & $57(274)$ & $21(276)$ & $<0.001$ \\
\hline Cohort $1, \mathrm{n}=348$ & 104 & 244 & \\
\hline Onset age, yrs $\pm \mathrm{SD}$ & $39 \pm 13$ & $53 \pm 16$ & $<0.001$ \\
\hline Disease duration, $\mathrm{yrs} \pm \mathrm{SD}$ & $3.0 \pm 1.5$ & $3.0 \pm 1.4$ & NS \\
\hline Last visit age, $\mathrm{yrs} \pm \mathrm{SD}$ & $41 \pm 14$ & $53 \pm 17$ & $<0.001$ \\
\hline RF positive, \% (n) & $86(89)$ & $68(166)$ & 0.011 \\
\hline ANA positive, $\%$ (n) & $38(40)$ & $19(46)$ & 0.007 \\
\hline Cohort $2, n=647$ & 188 & 459 & \\
\hline Onset age, yrs $\pm \mathrm{SD}$ & $36 \pm 14$ & $47 \pm 16$ & $<0.001$ \\
\hline Disease duration, $\mathrm{yrs} \pm \mathrm{SD}$ & $9 \pm 2.7$ & $10 \pm 2.8$ & NS \\
\hline Last visit age, $\mathrm{yrs} \pm \mathrm{SD}$ & $45 \pm 14$ & $56 \pm 16$ & $<0.001$ \\
\hline RF positive, \% (n) & 89 (167) & $75(344)$ & 0.001 \\
\hline ANA positive, $\%$ (n) & $53(100)$ & $23(106)$ & $<0.001$ \\
\hline Cohort $3, \mathrm{n}=801$ & 189 & 612 & \\
\hline Onset age, $\mathrm{yrs} \pm \mathrm{SD}$ & $29 \pm 14$ & $36 \pm 16$ & $<0.001$ \\
\hline Disease duration, $\mathrm{yrs} \pm \mathrm{SD}$ & $24 \pm 7$ & $25 \pm 9$ & NS \\
\hline Last visit age, $\mathrm{yrs} \pm \mathrm{SD}$ & $53 \pm 13$ & $61 \pm 15$ & $<0.001$ \\
\hline RF positive, \% (n) & $91(172)$ & $75(459)$ & $<0.001$ \\
\hline ANA positive, $\%$ (n) & $71(134)$ & $32(196)$ & $<0.001$ \\
\hline
\end{tabular}

RF: rheumatoid factor; ANA: antinuclear antibodies.

duration in both ethnic groups, while the proportion of patients who were ANA-positive increased markedly with disease duration in both groups, but particularly in NAN patients: $71 \%$ of NAN patients vs $32 \%$ of whites in those with disease duration $>15$ years were positive for ANA; $\mathrm{p}<$ 0.001 (Table 1).

NAN patients reported significantly higher pain, fatigue, and GDA VAS in all 3 cohorts compared to white patients (Table 2). In Cohort 1, mean scores were about 10-15 mm higher for NAN patients compared to white patients (pain VAS $50 \mathrm{~mm}$ vs $39 \mathrm{~mm}$, respectively, p < 0.001; fatigue VAS $55 \mathrm{~mm}$ vs $45 \mathrm{~mm}, \mathrm{p}=0.002$; and patient GDA VAS $45 \mathrm{~mm}$ vs $31 \mathrm{~mm}, \mathrm{p}<0.001$ ), and remained significantly higher for NAN patients in Cohorts 2 and 3 (Table 2). Mean physicians' GDA VAS scores were also significantly higher for NAN patients in all 3 cohorts $(29 \mathrm{~mm}$ vs $22 \mathrm{~mm}$ in Cohort $1, \mathrm{p}=0.002 ; 25 \mathrm{~mm}$ vs $20 \mathrm{~mm}$ in Cohort $2, \mathrm{p}<0.001$; and $26 \mathrm{~mm}$ vs $22 \mathrm{~mm}$ in Cohort 3, p < 0.001). Mean erythrocyte sedimentation rates (ESR) were about $5 \mathrm{~mm} / \mathrm{h}$ higher in NAN patients compared to whites in all 3 cohorts $(32 \mathrm{~mm} / \mathrm{h}$ vs $23 \mathrm{~mm} / \mathrm{h}$ in Cohort $1, \mathrm{p}=0.02 ; 30 \mathrm{~mm} / \mathrm{h}$ vs $25 \mathrm{~mm} / \mathrm{h}$ in Cohort 2, p $=0.003$; and $30 \mathrm{~mm} / \mathrm{h}$ vs $24 \mathrm{~mm} / \mathrm{h}$ in Cohort 3 , $\mathrm{p}=0.02$; Table 2).

Differences in functional limitations (mHAQ scores) varied among the 3 cohorts. Mean mHAQ scores were similar in those with early disease (Cohort 1, 0.58 in NAN patients 
Table 2. Disease activity and functional status. Patient total $n=1796$. All scores are mean \pm SD.

\begin{tabular}{|c|c|c|c|}
\hline Disease Activity Measure & $\begin{array}{c}\text { NAN, } \\
\mathrm{n}=481\end{array}$ & $\begin{array}{c}\text { White, } \\
\mathrm{n}=1315\end{array}$ & $\mathrm{p}$ \\
\hline Cohort $1, n=348$ & 104 & 244 & \\
\hline mHAQ score & $0.58 \pm 0.47$ & $0.47 \pm 0.42$ & NS \\
\hline mHAQ score at last visit & $0.90 \pm 0.69$ & $0.67 \pm 0.53$ & 0.002 \\
\hline Fatigue VAS, $100 \mathrm{~mm}$ & $55 \pm 22$ & $45 \pm 23$ & 0.002 \\
\hline Pain VAS, $100 \mathrm{~mm}$ & $50 \pm 23$ & $39 \pm 21$ & $<0.001$ \\
\hline Patient Global Disease Activity VAS, $100 \mathrm{~mm}$ & $45 \pm 25$ & $31 \pm 20$ & $<0.001$ \\
\hline MD Global Disease Activity VAS, $100 \mathrm{~mm}$ & $29 \pm 18$ & $22 \pm 13$ & 0.002 \\
\hline ESR mm/h & $32 \pm 31$ & $23 \pm 20$ & 0.02 \\
\hline Cohort 2, $\mathrm{n}=647$ & 188 & 459 & \\
\hline mHAQ score & $0.72 \pm 0.47$ & $0.56 \pm 0.49$ & $<0.001$ \\
\hline mHAQ score at last visit & $1.19 \pm 0.69$ & $0.86 \pm 0.68$ & $<0.001$ \\
\hline Fatigue VAS, $100 \mathrm{~mm}$ & $50 \pm 20$ & $45 \pm 23$ & 0.01 \\
\hline Pain VAS, $100 \mathrm{~mm}$ & $48 \pm 18$ & $39 \pm 20$ & $<0.001$ \\
\hline Patient Global Disease Activity VAS, $100 \mathrm{~mm}$ & $40 \pm 18$ & $30 \pm 19$ & $<0.001$ \\
\hline MD Global Disease Activity VAS, $100 \mathrm{~mm}$ & $25 \pm 12$ & $20 \pm 10$ & $<0.001$ \\
\hline ESR mm/h & $30 \pm 21$ & $25 \pm 21$ & 0.003 \\
\hline Cohort $3, n=801$ & 189 & 612 & \\
\hline mHAQ score & $0.77 \pm 0.50$ & $0.72 \pm 0.52$ & NS \\
\hline mHAQ score at last visit & $1.21 \pm 0.70$ & $1.02 \pm 0.72$ & 0.003 \\
\hline Fatigue VAS, $100 \mathrm{~mm}$ & $53 \pm 21$ & $49 \pm 22$ & 0.030 \\
\hline Pain VAS, $100 \mathrm{~mm}$ & $51 \pm 18$ & $45 \pm 20$ & $<0.001$ \\
\hline Patient Global Disease Activity VAS, $100 \mathrm{~mm}$ & $40 \pm 18$ & $33 \pm 18$ & $<0.001$ \\
\hline MD Global Disease Activity VAS, $100 \mathrm{~mm}$ & $26 \pm 11$ & $22 \pm 10$ & $<0.001$ \\
\hline ESR $\mathrm{mm} / \mathrm{h}$ & $30 \pm 23$ & $24 \pm 18$ & 0.02 \\
\hline
\end{tabular}

NAN: North American Native; mHAQ: modified health assessment questionnaire; VAS: visual analog scale; ESR: erythrocyte sedimentation rate.

vs 0.47 in whites, $\mathrm{p}=$ nonsignificant), but the mHAQ score at the last clinic visit for these patients was significantly higher in NAN patients $(0.90$ vs $0.67, \mathrm{p}=0.002)$. Differences were greatest for those in Cohort 2, where both the mean and the last visit mHAQ scores were higher in NAN patients $(0.72$ vs 0.56 , and 1.19 vs 0.86 , respectively, both $\mathrm{p}<0.001)$. For patients in Cohort 3 , mean mHAQ scores were similar, but last-visit mHAQ scores were again higher in NAN patients (1.21 vs $1.02, \mathrm{p}=0.003)$.

Mean tender and swollen joint counts were similar between NAN and white patients (Figure 1); however, the Lansbury score was significantly higher in NAN patients for all 3 cohorts (48 vs 33 in white patients in Cohort 1; 40 vs 32 in Cohort 2; and 44 vs 35 in Cohort 3; p $<0.001$ for all $3)$. This reflects the greater large joint involvement experienced by NAN patients with RA. Beginning in the early years of the disease, NAN patients are significantly more likely to have bilateral knee involvement (41\% compared to $24 \%$ of whites, $\mathrm{p}=0.016$ ), with trends to greater shoulder and elbow involvement. Differences are most apparent in those in Cohort 2, with more frequent bilateral shoulder, elbow, and knee involvement in NAN patients: $59 \%$ vs $45 \%, \mathrm{p}=0.007 ; 53 \%$ vs $34 \%, \mathrm{p}<0.001$; and $62 \%$ vs $48 \%$, $\mathrm{p}=0.007$, respectively (Figure 2). Even among those in Cohort 3, with an average disease duration of 25 years, NAN patients had more frequent elbow and knee involve- ment: $64 \%$ vs $52 \%$ bilateral elbow involvement, $\mathrm{p}=0.013$; $71 \%$ vs $64 \%$ bilateral knee involvement, $p=0.003$, in NAN versus white patients, respectively.

Treatment differences are also apparent. Treatment at the time of last clinical assessment is presented in Figure 3. Biologic treatment here includes only tumor necrosis factor (TNF- $\alpha$ ) inhibitors, because rituximab and abatacept were not readily available at the time of data collection. "Other" disease-modifying antirheumatic drugs (DMARD) include cyclosporine, oral and parenteral gold, penicillamine, and minocycline. Use of methotrexate (MTX), biologics, leflunomide, and other DMARD did not differ significantly for the 2 groups. But NAN patients in cohorts 2 and 3 (those patients with greater than 5 years of disease duration) were more likely than whites to be treated with hydroxychloroquine ( $40 \%$ vs $25 \%$ in Cohort $2, \mathrm{p}=0.002 ; 26 \%$ vs $17 \%$ in Cohort $3, \mathrm{p}=0.005)$ and sulfasalazine $(21 \%$ vs $12 \%$ in Cohort 2, $\mathrm{p}=0.012 ; 20 \%$ vs $9 \%$ in Cohort 3, $\mathrm{p}<0.001$ ). Analyses of treatment differences over the entire disease course showed very similar results (data not shown), and are reflected by the greater mean number of DMARD (including biologics) taken by NAN patients in Cohorts 2 and 3 during their disease course: 3.4 DMARD compared to 2.7 in whites in Cohort $2(\mathrm{p}=0.002)$; and 3.5 DMARD in NAN patients in Cohort 3 compared to 2.9 in whites, $(p=0.011$; Table 3). NAN patients in Cohort 2 were also more likely to Personal non-commercial use only. The Journal of Rheumatology Copyright (C) 2010. All rights reserved. 


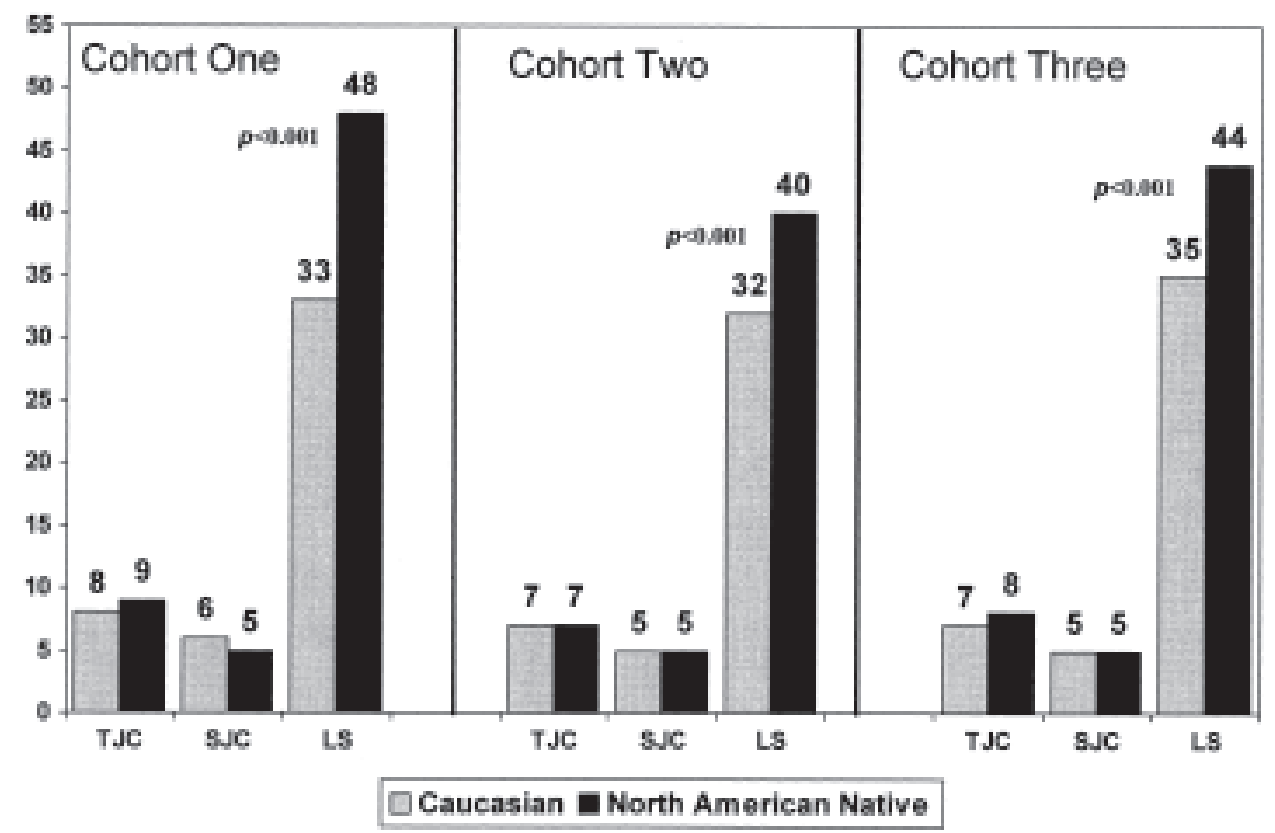

Figure 1. Mean joint counts in North American Native and white patients with rheumatoid arthritis. Cohort One: disease duration $\leq 5$ years; Cohort Two: disease duration $>5$ years, $<15$ years; Cohort Three: disease duration $>$ 15 years. TJC: tender joint count; SJC: swollen joint count; LS: Lansbury score.

be receiving combination DMARD therapy at their last clinic visit compared to whites $(57 \%$ vs $44 \%, \mathrm{p}=0.026)$. Combination therapy did not differ in those with early (Cohort 1) or very late (Cohort 3 ) disease, but in all 3 cohorts, NAN patients were significantly more likely to be receiving prednisone at their last clinical assessment: $54 \%$ vs $35 \%$ in Cohort $1(\mathrm{p}=0.013) ; 67 \%$ vs $46 \%$ in Cohort 2 (p $<0.001)$; and $74 \%$ vs $39 \%$ in Cohort 3 (p < 0.001 ; Table 3$)$.

\section{DISCUSSION}

The data from our study describe a phenotype of severe, early onset, seropositive RA in NAN patients in central Canada, compared to whites being followed at the same center. More frequent seropositivity for RF and ANA, higher RF titer, higher ESR, greater large joint involvement, higher physician-reported and patient-reported disease activity, and higher mHAQ scores are apparent in the early years of disease, become most evident in those with moderate disease duration, and are still noticeable, although perhaps less so, in patients with very longstanding disease. This is in the setting of treatment that appears more aggressive, with greater numbers of DMARD used, more frequent combination therapy, and more frequent use of corticosteroids. However, it is not clear whether these differences are due to biological factors, inadequate treatment, or additional as yet unknown factors.

The pattern of greater large joint involvement, particularly elbow and knee involvement, has not been described. In addition to higher Lansbury scores, it is likely that this pattern also contributes to the higher mHAQ scores reported by
NAN patients. Again, it is not clear whether this is part of a biologic phenotype or relates to treatment differences or other factors.

The earlier onset of RA in NAN patients described here has been observed in other NAN populations as well $2,3,16,22,23$. The implications of early disease onset, in addition to contributing to increased prevalence rates, include increased lifetime accumulation of deformity, disability, and drug toxicity, and perhaps higher premature mortality rates.

The high proportion of NAN patients positive for RF and ANA is perhaps indicative of biologic severity. RF, particularly at high titer, and ANA are generally considered to be poor prognostic markers in $\mathrm{RA}^{12,13,24}$. Several other populations of NAN patients with RA have also reported a frequency of $\mathrm{RF}>90 \%$, including the Yakima, Tlingit, Chippewa, Mazahua, Kiowa, and Oklahoma Indian patients, compared to the generally reported RF frequency of $75 \%-80 \%$ in patients with $\mathrm{RA}^{3,8,16,17,22,25,26}$. Similarly, the frequency of positive ANA in patients with RA was found to be higher than expected in these same NAN populations with RA, at 34\%-75\%. While we do not have anticyclic citrullinated peptide (anti-CCP) data for these cohorts, a subset of 266 of these same patients, participating in another study at our center, were found to be $82 \%$ anti-CCP-positive ${ }^{27}$. This population is also known to have a very high prevalence of the shared epitope: in El-Gabalawy, et al, 75\% of patients with RA and unaffected controls were found to have the shared epitope ${ }^{27}$, and in another study of juvenile RA in NAN children, $63 \%$ of RA Personal non-commercial use only. The Journal of Rheumatology Copyright @ 2010 . All rights reserved. 


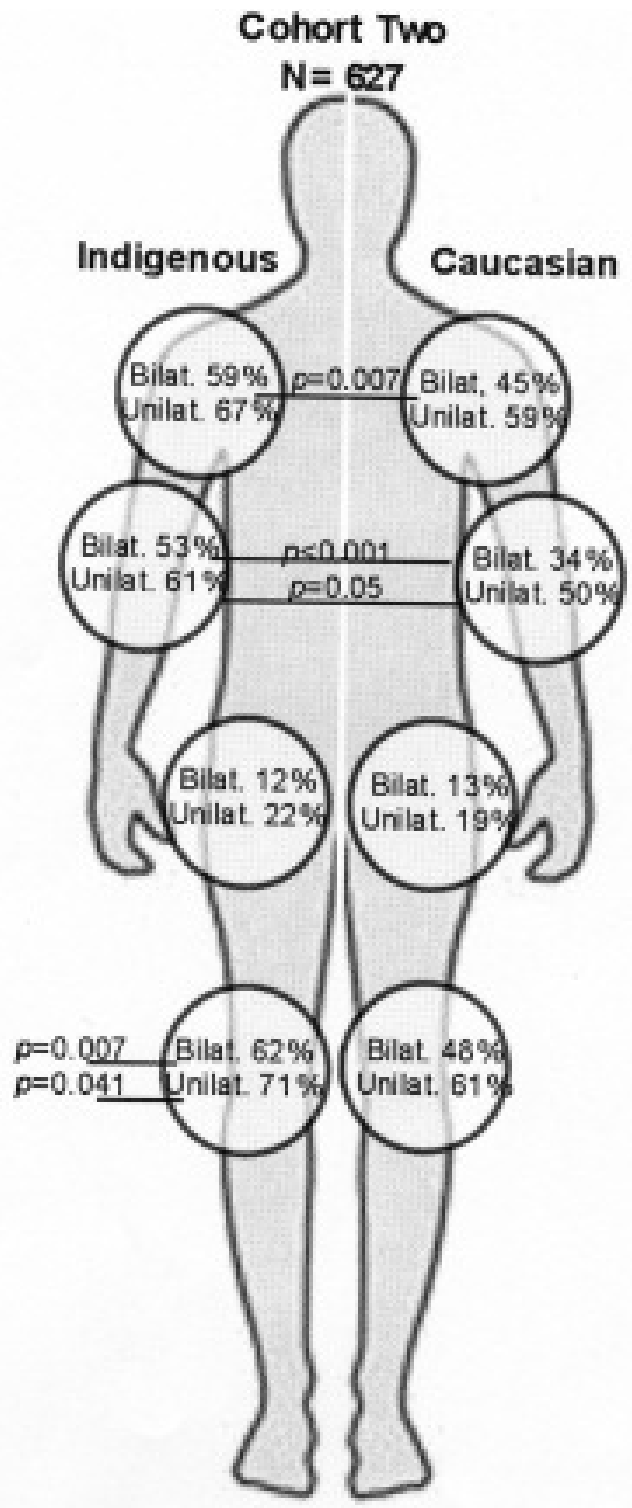

Figure 2. Large joint involvement in North American Native and white patients with rheumatoid arthritis, Cohort Two, disease duration $>5$ years, $<15$ years.

patients and $59 \%$ of controls had the shared epitope ${ }^{28}$. These serologic differences may suggest greater biologic severity or susceptibility.

Cigarette smoking may also play a role in this population. Reported smoking rates for Canadian NAN adults are high, at $59 \%$, more than twice the rate of $24 \%$ for non-NAN Canadian adults ${ }^{29,30}$. While cigarette smoking has been unambiguously shown to increase the risk of developing $\mathrm{RA}^{31,32}$, it is also clear that smoking acts in combination with genetic and other environmental risk factors. A large Swedish epidemiologic study suggested that smoking is strongly associated with anti-CCP-positive RA, and our study among others suggests a gene-environment interaction between smoking and shared epitope alleles ${ }^{33,34,35}$. More recently, a lesser response to both MTX and TNF- $\alpha$ inhibitors was also demonstrated in smokers compared to nonsmokers ${ }^{36}$.

Other factors may also play a role. Many NAN patients live in remote locations, up to $1000 \mathrm{~km}$ or more from our specialist clinics, making followup and monitoring for treatment efficacy and safety difficult. We have shown that, in spite of indicators of severe disease, NAN patients have less frequent followup visits to our clinic compared to whites ${ }^{37}$. While physician visits and hospitalizations are covered for all Manitobans under the same universal, publicly funded healthcare system, NAN Manitobans are also funded for travel to medical appointments through a federal program. In spite of this, an analysis of healthcare use by Manitoba NAN people showed overall reduced contact with specialists for NAN compared to other Manitobans, unrelated to either geography or health indicators ${ }^{38,39}$.

It is probable that differences in insurance coverage for medications also play a role. Treaty-status NAN Manitobans have coverage for medications through a federally funded program, while all other Manitobans are covered through a provincially funded plan. The federally funded plan for NAN people has stricter guidelines and requires more drug failures to access medications such as leflunomide, cyclosporine, and TNF- $\alpha$ inhibitors. It is likely that this accounts for some of the higher frequency of sulfasalazine and hydroxychloroquine use observed in NAN patients, as well as the similar rates of biologic use in spite of more severe disease.

There are some limitations to our study. First, we do not have radiologic data, and therefore cannot comment on joint damage. More importantly, our database does not contain information on the interval between disease onset and initiation of treatment. While date of onset of disease is recorded at the first visit regardless of the stage of a patient's disease, treatment received prior to attending our center is not reliably recorded. Therefore patients may have had treatment initiated by primary care physicians or other rheumatologists prior to being seen at our center; shortages of rheumatologists over the years also resulted in delayed referrals and treatment initiation. Although prior studies in Manitoba have documented a high rate of general physician visits for arthritis in NAN people ${ }^{37}$, underreferral to specialists in general compared to non-NAN people has also been reported, in spite of worse health indicators ${ }^{38,39}$. Therefore it is possible that the worse outcome in NAN patients may be due in part to delayed treatment, or a missed "window of opportunity." The difference in disease severity is not likely to be due to disproportionate referral rates of severe patients to our center. Our hospital functions as a tertiary referral site for both NAN and all other Manitobans. In addition, all rheumatologists in the province practice in our city, and over the years of the study, the majority have been located at our hospital site. 


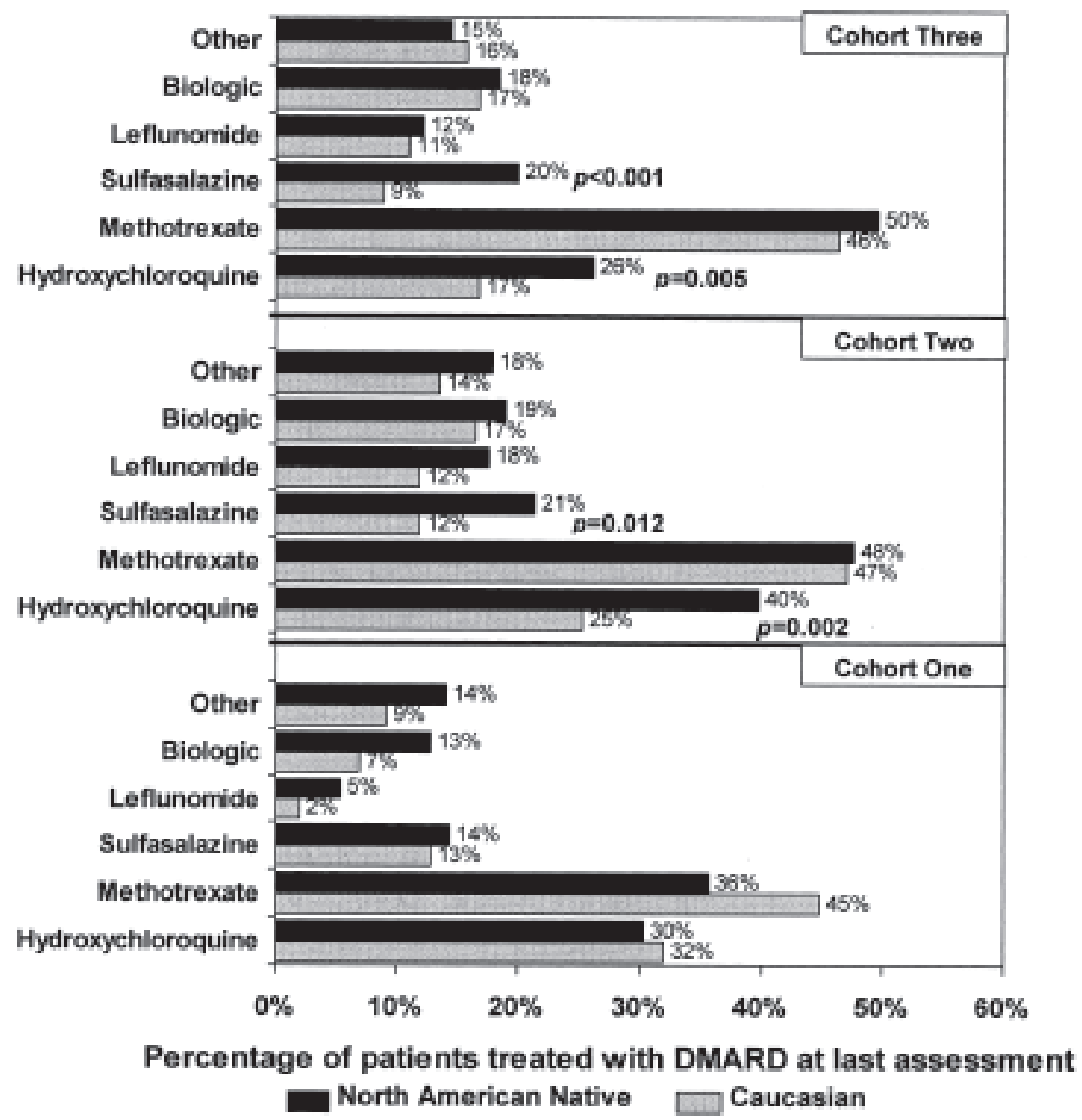

Figure 3. Disease-modifying antirheumatic drug (DMARD) treatment at time of last clinical assessment. Cohort One: disease duration $\leq 5$ years; Cohort Two: disease duration $>5$ years, $<15$ years; Cohort Three: disease duration $>15$ years. "Other" treatment includes cyclosporine, oral and parenteral gold treatment, penicillamine, and minocycline. Percentages add up to $>100$ because patients may be taking more than 1 DMARD concomitantly.

Table 3. Treatment differences. Patient total $\mathrm{n}=1796$.

\begin{tabular}{|c|c|c|c|}
\hline Type of Treatment & $\begin{array}{l}\text { NAN, } \\
\mathrm{n}=481\end{array}$ & $\begin{array}{c}\text { White, } \\
\mathrm{n}=1315\end{array}$ & $\mathrm{p}$ \\
\hline \multicolumn{4}{|c|}{ Prednisone treatment at last visit, $\%$} \\
\hline Cohort $1, \mathrm{n}=348$ & 54 & 35 & 0.013 \\
\hline Cohort $2, \mathrm{n}=647$ & 67 & 46 & $<0.001$ \\
\hline Cohort $3, \mathrm{n}=801$ & 74 & 39 & $<0.001$ \\
\hline \multicolumn{4}{|c|}{ Combination treatment at last visit, \% } \\
\hline Cohort $1, \mathrm{n}=348$ & 41 & 36 & NS \\
\hline Cohort $2, \mathrm{n}=647$ & 57 & 44 & 0.026 \\
\hline Cohort $3, \mathrm{n}=801$ & 48 & 39 & NS \\
\hline \multicolumn{4}{|c|}{ Number of DMARD (ever), mean number \pm SD } \\
\hline Cohort $1, \mathrm{n}=348$ & $1.9 \pm 1.4$ & $1.6 \pm 1.5$ & NS \\
\hline Cohort $2, n=647$ & $3.4 \pm 2.0$ & $2.7 \pm 2.2$ & 0.002 \\
\hline Cohort $3, \mathrm{n}=801$ & $3.5 \pm 2.3$ & $2.9 \pm 2.6$ & 0.011 \\
\hline
\end{tabular}

NAN: North American Native; DMARD: disease-modifying antirheumatic drug.
While our study documents aggressive disease with worse outcomes in NAN patients with RA, which has long been suspected by those caring for them, it raises many questions. There is an urgent need to further define those factors that may be contributing to poor outcomes in NAN patients with RA, in order to develop more timely and appropriate interventions for this rapidly growing segment of the Canadian population.

\section{REFERENCES}

1. Atkins C, Reuffel L, Roddy J, Platts M, Robinson H, Ward R. Rheumatic disease in the Nuu-Chah-Nulth native Indians of the Pacific Northwest. J Rheumatol 1988;15:684-90.

2. Beasley RP, Willkens RF, Bennett PH. High prevalence of rheumatoid arthritis in Yakima Indians. Arthritis Rheum 1973;16:743-8.

3. Boyer GS, Templin DW, Lanier AP. Rheumatic diseases in Alaskan Indians of the southeast coast: high prevalence of rheumatoid arthritis and systemic lupus erythematosus. J Rheumatol 
1991;18:1477-84

4. Del Puente A, Knowler WC, Pettitt DJ, Bennett PH. High incidence and prevalence of rheumatoid arthritis in Pima Indians. Am J Epidemiol 1989;129:1170-8.

5. Elliott BA, Johnson KM, Leff RD, Day JJ. Arthritis in Indian country: determining the prevalence and effects. Ethn Dis 2000;10:224-31.

6. Harvey J, Lotze M, Stevens MB, Lambert G, Jacobson D. Rheumatoid arthritis in a Chippewa Band. I. Pilot screening study of disease prevalence. Arthritis Rheum 1981;24:717-21.

7. Hill RH, Robinson HS. Rheumatoid arthritis and ankylosing spondylitis in British Columbia Indians: their prevalence and the challenge of management. Can Med Assoc J 1969;100:509-11.

8. Willkens RF, Blandau RL, Aoyama DT, Beasley RP. Studies of rheumatoid arthritis among a tribe of Northwest Indians. J Rheumatol 1976;3:9-14.

9. Oen KG, Cheang M. Epidemiology of chronic arthritis in childhood. Semin Arthritis Rheum 1996;26:575-91.

10. Mauldin J, Cameron HD, Jeanotte D, Solomon G, Jarvis JN. Chronic arthritis in children and adolescents in two Indian health service user populations. BMC Musculoskelet Disord 2004;5:30

11. Rosenberg AM, Petty RE, Oen KG, Schroeder ML. Rheumatic diseases in Western Canadian Indian children. J Rheumatol 1982;9:589-92.

12. Masi AT, Maldonado-Cocco JA, Kaplan SB, Feigenbaum SL, Chandler RW. Prospective study of the early course of rheumatoid arthritis in young adults: comparison of patients with and without rheumatoid factor positivity at entry and identification of variables correlating with outcome. Semin Arthritis Rheum 1976;4:299-326.

13. Kaarela K. Prognostic factors and diagnostic criteria in early rheumatoid arthritis. Scand J Rheumatol Suppl 1985;57:1-54

14. Hirsch R, Lin JP, Scott WW Jr, Ma LD, Pillemer SR, Kastner DL, et al. Rheumatoid arthritis in the Pima Indians: the intersection of epidemiologic, demographic, and genealogic data. Arthritis Rheum 1998:41:1464-9.

15. Willkens RF, Nepom GT, Marks CR, Nettles JW, Nepom BS. Association of HLA-Dw16 with rheumatoid arthritis in Yakima Indians. Further evidence for the "shared epitope" hypothesis. Arthritis Rheum 1991;34:43-7.

16. Templin DW, Boyer GS, Lanier AP, Nelson JL, Barrington RA, Hansen JA, et al. Rheumatoid arthritis in Tlingit Indians: clinical characterization and HLA associations. J Rheumatol 1994:21:1238-44.

17. Heimgartner E, Rosenthal M. [Rheumatoid arthritis in an Indian population (Mazahua) in the Mexican plateau]. Bol Oficina Sanit Panam 1979;86:283-92.

18. Hallet B. Aboriginal people in Manitoba. Ottawa: Service Canada; 2006.

19. Arnett FC, Edworthy SM, Bloch DA, McShane DJ, Fries JF, Cooper NS, et al. The American Rheumatism Association 1987 revised criteria for the classification of rheumatoid arthritis. Arthritis Rheum 1988;31:315-24.

20. Lansbury J, Haut DD. Quantitation of the manifestations of rheumatoid arthritis. 4. Area of joint surfaces as an index to total joint inflammation and deformity. Am J Med Sci 1956;232:150-5.

21. Lansbury J. The pooled index. J Rheumatol 1977;4:445-6.

22. Harvey J, Lotze M, Arnett FC, Bias WB, Billingsley LM, Harvey E, et al. Rheumatoid arthritis in a Chippewa band. II. Field study with clinical serologic and HLA-D correlations. J Rheumatol 1983;10:28-32.

23. Jacono J, Jacono B, Cano P, Segami M, Rubin L. An epidemiological study of rheumatoid arthritis in a northern Ontario clinical practice: the role of ethnicity. J Adv Nurs 1996;24:31-5.
24. Winska WH, Thompson K, Young A, Corbett M, Shipley M, Hay F. $\operatorname{IgA}$ and $\operatorname{IgM}$ rheumatoid factors as markers of later erosive changes in rheumatoid arthritis (RA). Scand J Rheumatol Suppl 1988;75:238-43.

25. Goodyear CS, Tighe H, McInnes IB. Rheumatoid factors and other autoantibodies in rheumatoid arthritis. In: Firestein GS, Budd RC, Harris ED, McInnes IB, Ruddy S, Sergent JS, editors. Kelley's textbook of rheumatology. 8th ed. Philadelphia: Saunders; 2009:755-67.

26. Scofield RH, Fogle M, Rhoades ER, Harley JB. Rheumatoid arthritis in a United States Public Health Service Hospital in Oklahoma: serologic manifestations in rheumatoid arthritis vary among tribal groups. Arthritis Rheum 1996;39:283-6.

27. El-Gabalawy HS, Robinson DB, Hart D, Elias B, Markland $\mathrm{J}$, Peschken CA, et al. Immunogenetic risks of anti-cyclical citrullinated peptide antibodies in a North American Native population with rheumatoid arthritis and their first-degree relatives. J Rheumatol 2009;36:1130-5.

28. Oen K, Schroeder M, Jacobson K, Anderson S, Wood S, Cheang M, et al. Juvenile rheumatoid arthritis in a Canadian First Nations (aboriginal) population: onset subtypes and HLA associations. J Rheumatol 1998;25:783-90.

29. Smoking in Canada: an overview. Ottawa: Health Canada; 2003.

30. First Nations Regional Longitudinal Health Survey (RHS) 2002/03. Ottawa: Assembly of First Nations; March 2007.

31. Oliver JE, Silman AJ. Risk factors for the development of rheumatoid arthritis. Scand J Rheumatol 2006;35:169-74.

32. Olsson AR, Skogh T, Wingren G. Aetiological factors of importance for the development of rheumatoid arthritis. Scand J Rheumatol 2004;33:300-6.

33. Klareskog L, Stolt P, Lundberg K, Kallberg H, Bengtsson C, Grunewald J, et al. A new model for an etiology of rheumatoid arthritis: smoking may trigger HLA-DR (shared epitope)-restricted immune reactions to autoantigens modified by citrullination. Arthritis Rheum 2006;54:38-46.

34. Lundstrom E, Kallberg H, Alfredsson L, Klareskog L, Padyukov L. Gene-environment interaction between the DRB1 shared epitope and smoking in the risk of anti-citrullinated protein antibody-positive rheumatoid arthritis: all alleles are important Arthritis Rheum 2009;60:1597-603

35. Padyukov L, Silva C, Stolt P, Alfredsson L, Klareskog L. A gene-environment interaction between smoking and shared epitope genes in HLA-DR provides a high risk of seropositive rheumatoid arthritis. Arthritis Rheum 2004;50:3085-92.

36. Saevarsdottir S, Wedren S, Seddighzadeh M, Askling J, Padyukov $\mathrm{L}$, Alfredsson L, et al. Smoking is associated with non-response to methotrexate and to anti-TNF treatment in patients with rheumatoid arthritis. Results From the Swedish EIRA Study [abstract]. Arthritis Rheum 2009;60 Suppl:635.

37. Barnabe C, Elias B, Bartlett J, Roos L, Peschken C. Arthritis in aboriginal Manitobans: evidence for a high burden of disease. J Rheumatol 2008;35:1145-50.

38. Martens PJ, Sanderson D, Jebamani L. Health services use of Manitoba First Nations people: is it related to underlying need? Can J Public Health 2005;96 Suppl 1:S39-44.

39. Martens PJ, Bond R, Jebamani L, Burchill C, Roos NP, Derksen S, et al. The health and health care use of registered First Nations people living in Manitoba: a population-based study. Winnipeg: Manitoba Centre for Health Policy; 2002. 